\title{
ENGENHO D'ARTE DO SERTÃO DE CRATEÚS NA FORMAÇÃO CIDADÃ
}

DOI: 10.37702/2175-957X.COBENGE.2021.3740

Kennedy da Silva Ramos - kennedyramos@crateus.com.br

Universidade Federal do Ceará

Rua: Gentil Barreiras 150

63702-260 - Crateús - CE

Ana Chirlem Soares Texeira - chirlem.texeira@aluno.uece.br

Universidade Estadual do Ceará

Vila Xavier 74

63710-990 - Crateús - CE

Tiany Guedes Cota - tianycota@crateus.ufc.br

Universidade Federal do Ceará

Rua Clovis Bevilaqua 1188

63700-155 - Crateús - CE

Bruno Anchieta Viana - bruno.anchieta@alu.ufc.br

Universidade Federal do Ceará

Lagoa da Areia s/n

63740-000 - Novo Oriente - CE

João Pedro de Abreu Mesquita - joaozao67@hotmail.com

Universidade Federal do Ceará

Sítio Cajueiro S/N

62380-000 - Guaraciaba do Norte - CE

Resumo: Engenho d'arte do Sertão de Crateús é um projeto de caráter extensionista multidisciplinar que busca através da comunidade acadêmica do campus gerar melhorias físicas que impactam no bem-estar da própria comunidade acadêmica. Através de ações, nos eixos temáticos arte ou cultural, são realizadas ações no campus Crateús da Universidade Federal do Ceará que alcançam a todos que vivenciam o campus. Além disso, o protagonismo maior da elaboração e execução do projeto é dos discentes que realizam as atividades auxiliados pelos professores e servidores do projeto e expõem para a comunidade 


\section{COBENGE eIV Simpósio Internacional

acadêmica. Esta comunidade tem se mostrado bastante receptiva a este tipo de ação e tem avaliado de forma positiva a atuação do projeto. Engenho d'arte tem contribuído para a construção de uma formação cidadã através da atuação no espaço físico acadêmico, com melhorias por meio de jogos, engenhocas e arte que misturam engenharia,criatividade e humanidade.

Palavras-chave: Engenho d'arte do Sertão de Crateús. Formação Cidadã. Bem-estar comunitário. 


\section{ENGENHO D'ARTE DO SERTÃO DE CRATEÚS NA FORMAÇÃO CIDADÃ}

\section{INTRODUÇÃO}

A educação superior tem papel maior que apenas fornecer técnica. Desta maneira, ela também tem importância na formação cidadã do indivíduo como guia de si e da comunidade, sendo sujeito ativo em temáticas sociais e culturais locais (SILVA, 95). Com isso, o ambiente acadêmico deve fornecer condições para a criação de ações que proporcionem que as pessoas atuem na construção de sua formação cidadã. Tais condições são buscadas no projeto apresentado.

Engenho d'arte do Sertão de Crateús é um projeto de caráter extensionista multidisciplinar desenvolvido pela Engenharia de Minas da Universidade Federal do Ceará (UFC) campus Crateús em parceria com a prefeitura do campus, Pró-reitoria de Extensão e a Secretaria de Cultura Artística (Secult Arte UFC). O projeto objetiva promover um ambiente físico mais agradável no campus Crateús para comunidade acadêmica e promover o caráter cidadão dos participantes.

Esse é composto por dois professores, dois técnicos administrativos, quatro alunos da engenharia de minas e uma de pedagogia. E realiza ações de extensão nos eixos temáticos: cultural e artístico, desde março de 2020. Cada ação exporá um eixo temático e os eixos são repetidos ao longo do projeto.

A motivação do projeto foi devido a percepção social da necessidade de aumentar os elementos que trazem bem-estar para a comunidade acadêmica. Além disso, também surgiu com a necessidade de contribuir para o desenvolvimento da formação cidadã requerida no parágrafo $1^{\circ}$ do Artigo $3^{\circ}$ da Resolução $N^{\circ} 2$ das Diretrizes Curriculares Nacionais (DCN) do Curso de Graduação em Engenharia.

As DCN reforçam a necessidade que os egressos tenham competência e habilidade variadas, sendo um perfil humanístico, reflexivo, criativo, cooperativo uma parte do esperado (BRASIL, 2019) e novas propostas educacionais incentivam a aprendizagem, através do protagonismo do aluno na resolução de problemas por metodologias ativas (MACEDO et al., 2018). Este fato e a necessidade de a própria comunidade acadêmica contribuir com a melhora do campus e o bem-estar acadêmico caracterizam a adequação educacional do projeto.

\section{METODOLOGIA}

A metodologia do projeto Engenho d'arte do Sertão de Crateús iniciou-se pela observação da carência que a comunidade acadêmica do campus Crateús possui de novos atrativos que melhorem o bem-estar físico da comunidade acadêmica, das implantação das novas DCN que reforçam a necessidade do perfil humanista do egresso, caráter extensionista da universidade e da necessidade de metodologias ativas de aprendizagem. 
Assim, escreveu-se o escopo do projeto baseado nestas necessidades e buscou a licença da prefeitura do campus para atuação do projeto. Posteriormente o projeto foi submetido a editais de bolsa de extensão e arte da UFC, onde foi contemplado em ambos os editais, possibilitando bolsas para alguns alunos.

Reunido os integrantes do projeto foi realizado o levantamento das atividades e o cronograma de execução. Sendo que o cronograma de execução normal foi impactado pela epidemia de Covid-19, porém várias ações foram realizadas, sendo estas no eixo cultural e artístico.

As ações sempre buscaram o protagonismo dos alunos, a mistura dos conhecimentos adquiridos, a construção de peças novas e atraentes para a comunidade acadêmica e melhorias físicas para o campus. Assim, foram planejadas atividades nos eixos do projeto, sendo estas:

1. Construção de jogos (eixo cultural);

2. Construção de brinquedos (eixo cultural);

3. Construção de peças artísticas (eixo artístico).

A primeira atividade foi pensada para explorar a interação entre os alunos que muitas vezes ficam sozinhos. Desta forma, os bolsistas sugeriram a construção de jogos e 0 coordenador sugeriu jogos de tabuleiros, pois são fáceis de transportar e de aprender. Com isso, se utilizou das ferramentas do campus, Figura 1, e os alunos construíram três jogos, Figura 2, estes são: jogo de dama, resta um e jogo da velha.

Figura 1 - Construção dos jogos de tabuleiro.
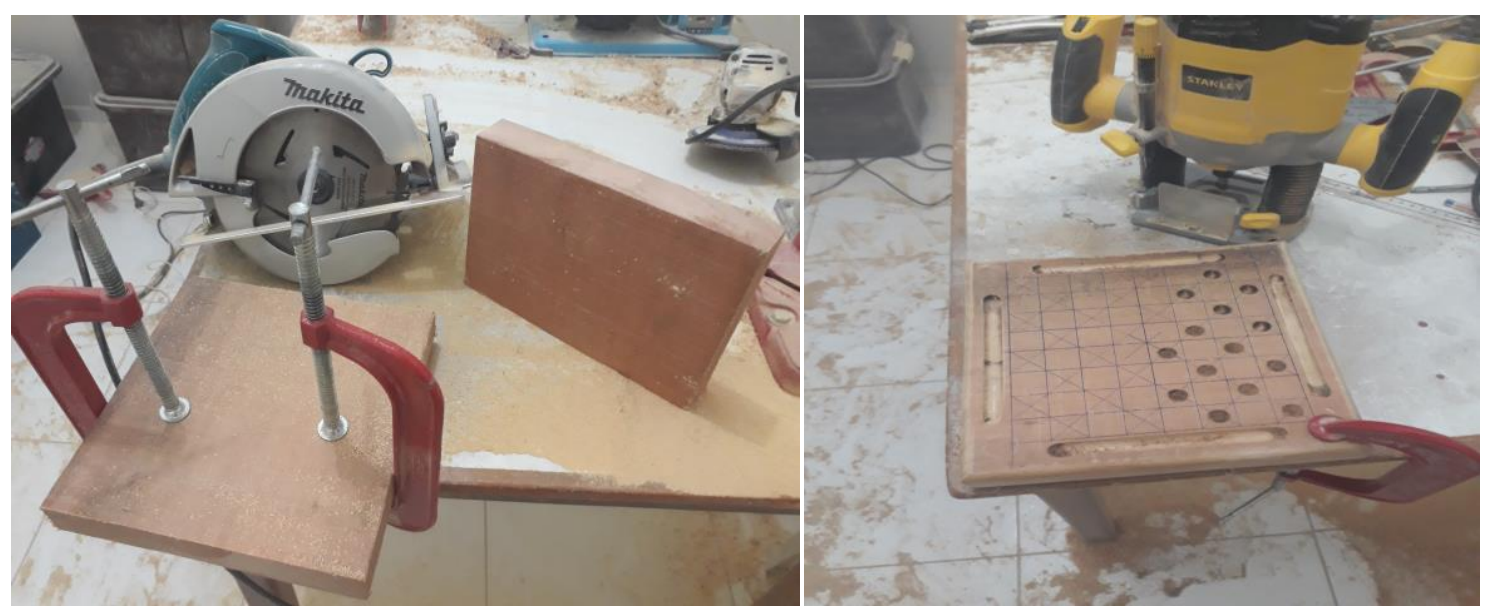

Fonte: Autores 
Figura 2 -Jogos de tabuleiro:jogo da velha (esquerda), resta um (centro), dama (direita)
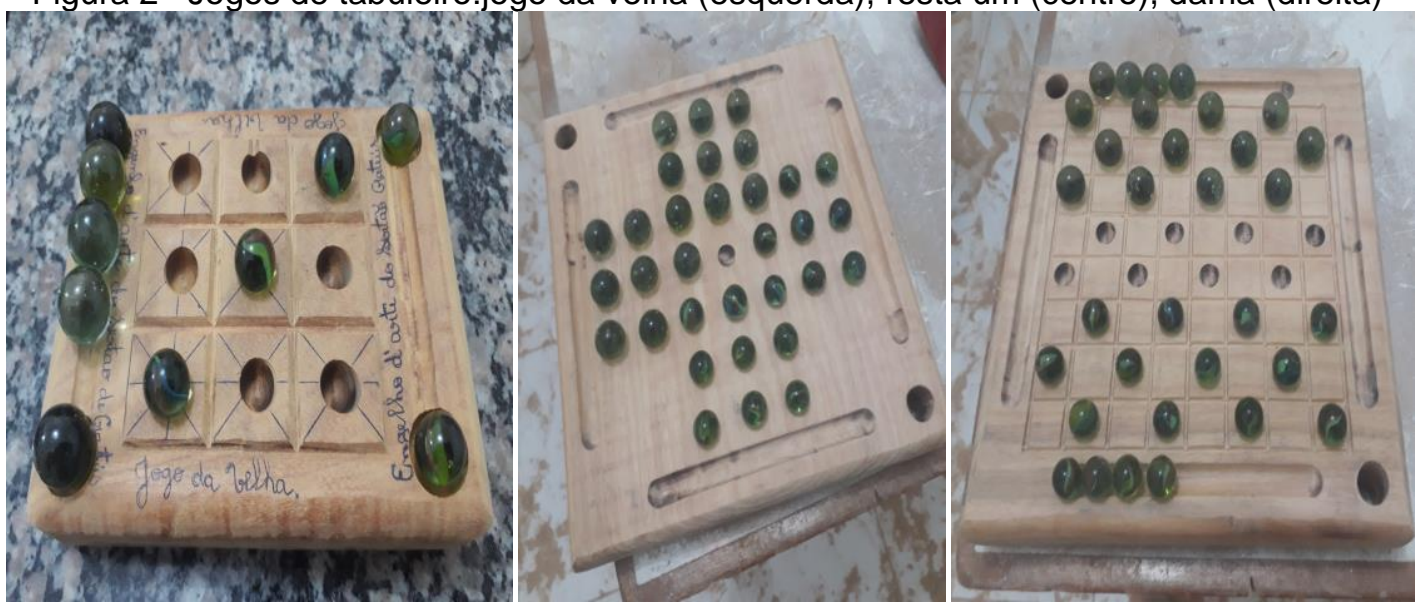

Fonte: Autores

A segunda atividade foi pensada para valorizar os espaços no sentido de a comunidade acadêmica poder brincar em locais comuns, como a portaria. Assim, foram construídas engenhocas que utilizaram o conhecimento de engenharia dos alunos e os materiais disponíveis localmente, Figura 3.

Figura 3 - Brinquedos engenhocas construídos
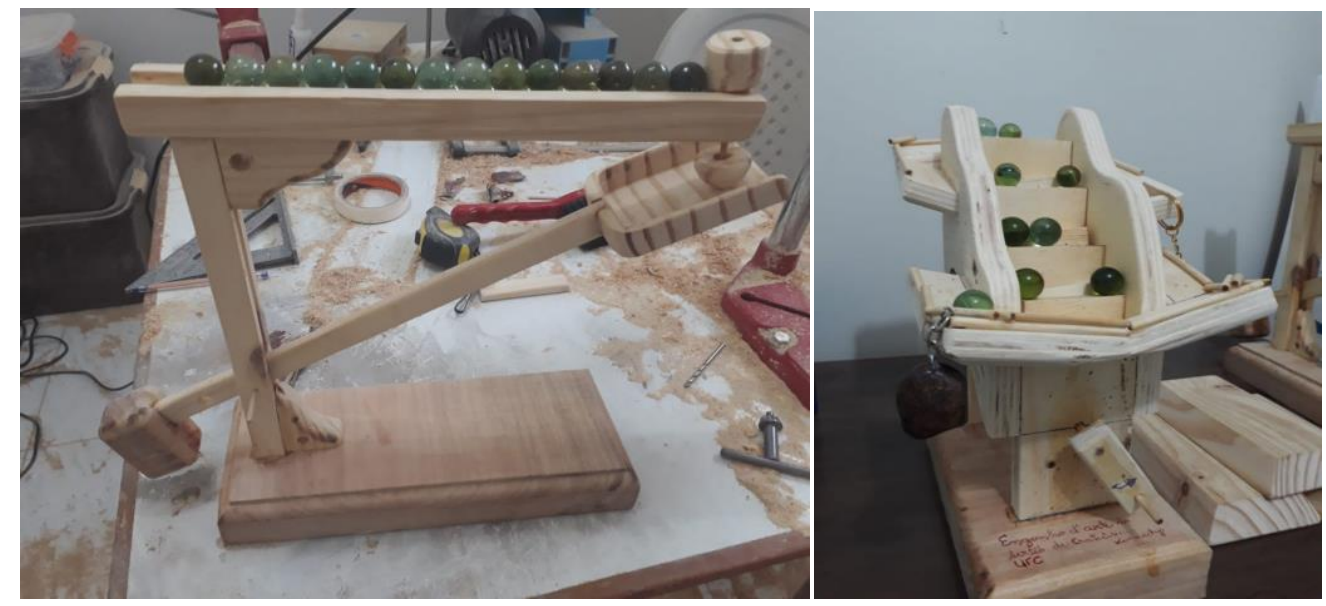

Fonte: Autores

A terceira atividade foi a elaboração de peças artísticas que misturam engenharia e apelo visual. Assim, foram construídas peças de madeira que foram expostas na secretaria, coordenação da Engenharia de Minas e Hall de entrada do bloco administrativo, Figura 4. 
Figura 4 - Peças artísticas: urna de votação (esquerda), barras de ouro de madeira (centro), suporte mágico de garrafa (esquerda).
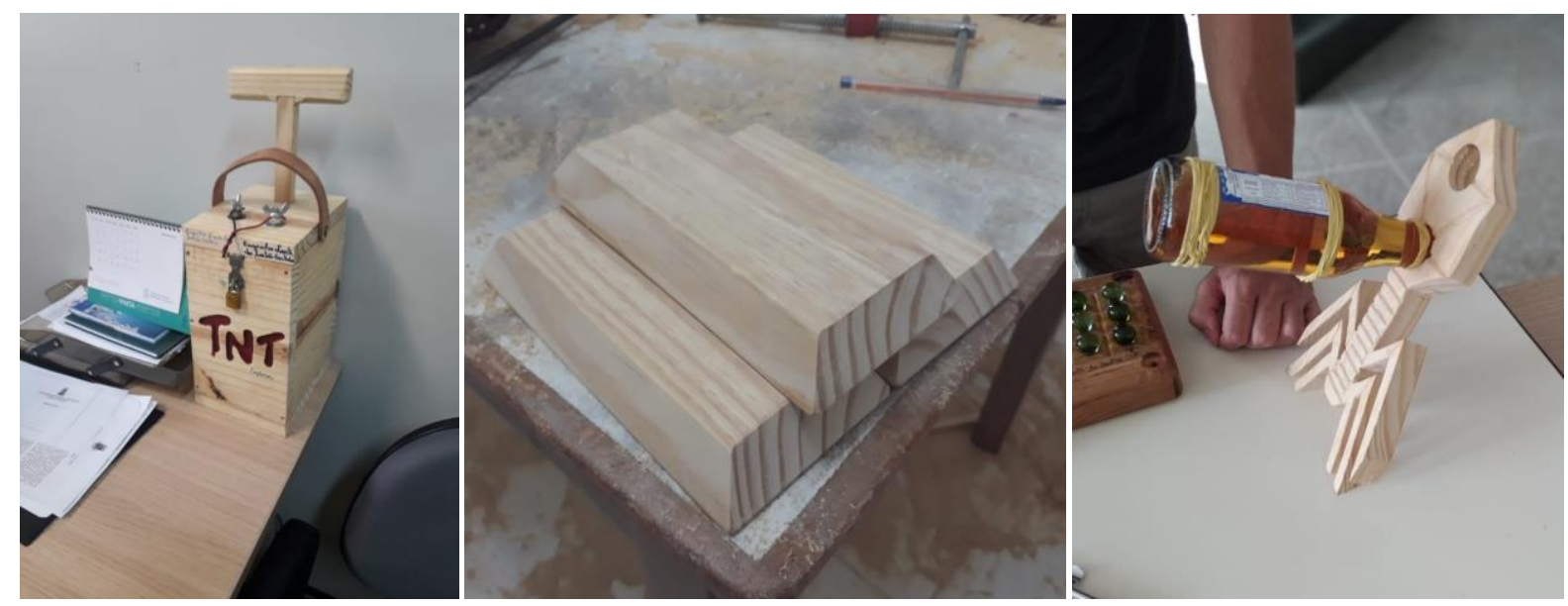

Fonte: Autores

Assim, as atividades foram expostas. O cronograma das atividade seria de: construção e exposição das peças a cada mês, seguindo o eixo temático do mês, porém devido a pandemia o projeto construiu todas as peças mostradas em Fevereiro e expôs em Fevereiro e Março para os discentes e docentes, de forma presencial, porém as peças continuam expostas para os servidores em atividades essenciais no campus. Para poder continuar a exposição das peças o projeto criou uma página no Instagram: engarte_crateus.

\section{RESULTADOS E DISCUSSÃO}

Como resultado teve a elaboração de vinte e três ações nos eixos temáticos, sendo dezesseis no eixo arte e sete no eixo cultural. Estas ações atingiram aproximadamente 150 pessoas do campus Crateús nos meses de Fevereiro de 2020 e Abril de 2021 e alguns visitantes, como avaliadores do MEC, palestrantes externos e servidores de outros campus e continuam atingindo em média 30 pessoas (seguranças, porteiros, auxiliares de limpeza, jardineiro, auxiliares de manutenção, técnicos administrativos).

Inicialmente os discentes ficaram tímidos com as peças expostas ao ar livre, porém com o tempo alguns que interagiram com as peças incentivavam que os demais começassem a interagir com a exposição. Isto levou a um movimento de uso coletivo das peças, Figura 5. 
Figura 5 - Interação da comunidade acadêmica com as exposições.
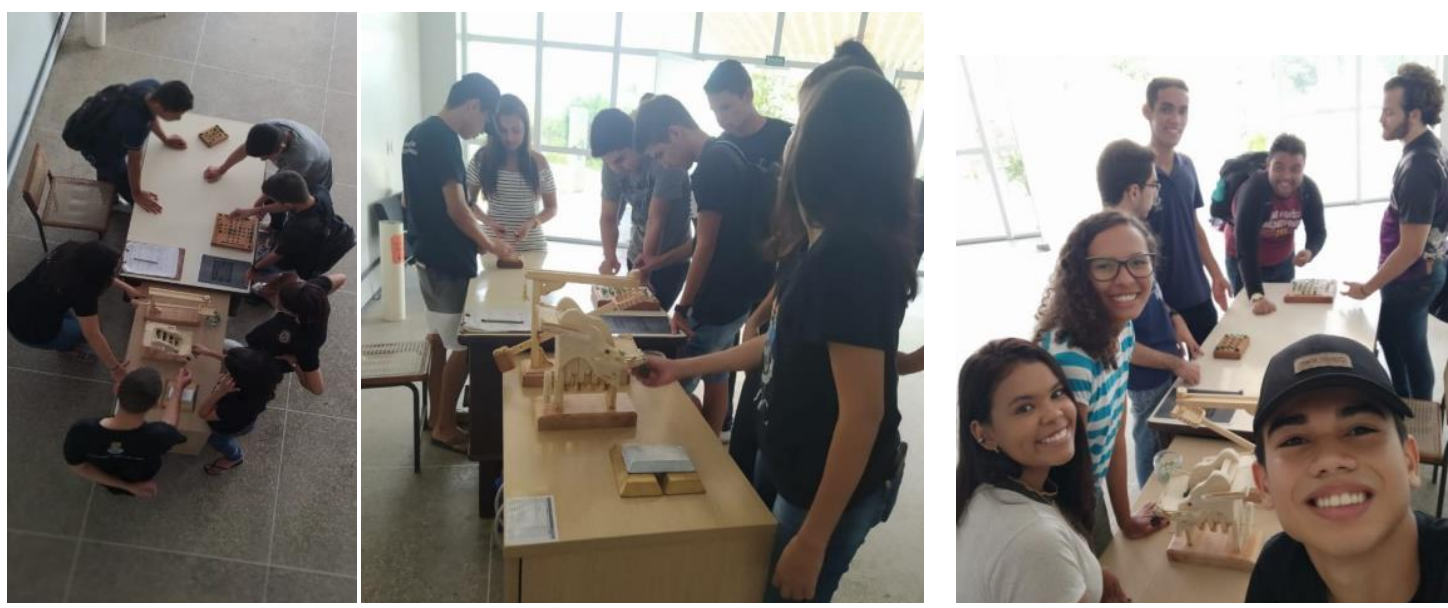

Fonte: Autores

A primeira ação foi a exposição no Hall de entrada dos jogos de tabuleiro: dama, resta um e jogo da velha, Figura 6. Esta ação teve como resultado uma grande procura por grupos de alunos que interagiram de forma competitiva nos intervalos das aulas. Além disso, as peças contribuíram com: a diversão, distração, raciocínio lógico, cooperação, convívio social.

Figura 6 - Jogos de tabuleiro em uso.

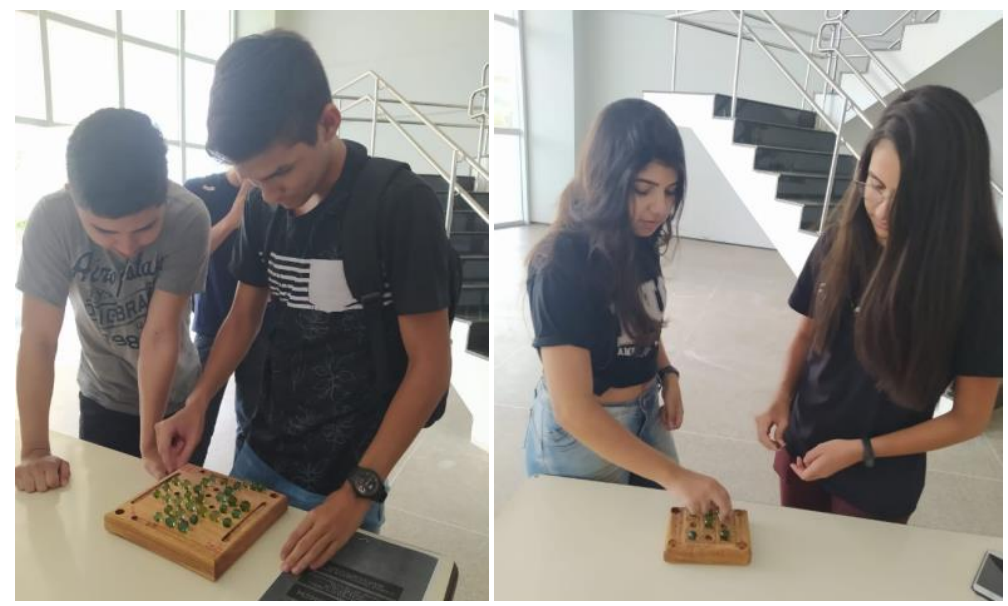

Fonte: Autores

A segunda ação também foi exposta no Hall de entrada, devido a ser um lugar de grande circulação da comunidade acadêmica. A exposição teve como peças as engenhocas, Figura 7, que misturam arte, diversão e engenharia. Esta exposição teve como resultado grande procura, pois as peças expostas são pouco conhecidas e muito interativas com o público, além disso despertou o interesse pelo funcionamento dos mecanismos. 
Figura 7 - Jogos de tabuleiro em uso.
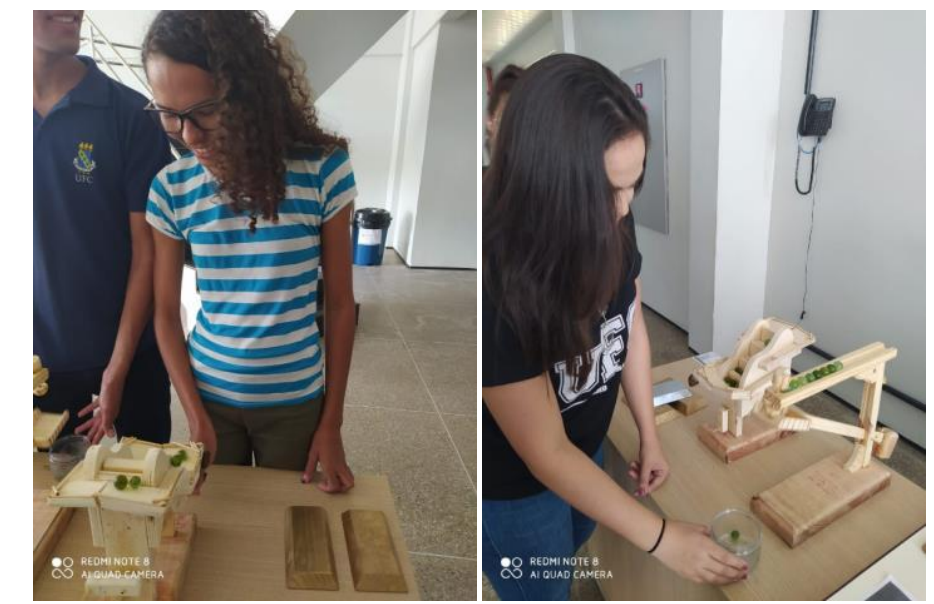

Fonte: Autores

A terceira ação está no eixo artístico, diferente das duas anteriores do eixo cultural, foram expostas em diferentes lugares, como na secretaria, coordenação da Engenharia de Minas e Hall do bloco administrativo, Figura 8. Teve como resultado a atração da atenção de muitos servidores do campus, porque estes ficaram admirados com a originalidade das peças. Por exemplo:uma das peças expostas foi uma urna em forma de explosor antigo de TNT, que foi utilizada em votações e sugestões de melhoria na secretaria. A outra foi barras de madeira pintadas de dourado e prata simulando barras de ouro e prata. E a última foi um suporte em equilíbrio dinâmico de garrafa. Estas peças foram várias vezes fotografadas, mesmo em self, por funcionário e alunos.

Figura 8 - Peças artísticas: Urna exposor (esquerda), barras de ouro e prata (centro) e suporte mágico em forma de vírus (direita).
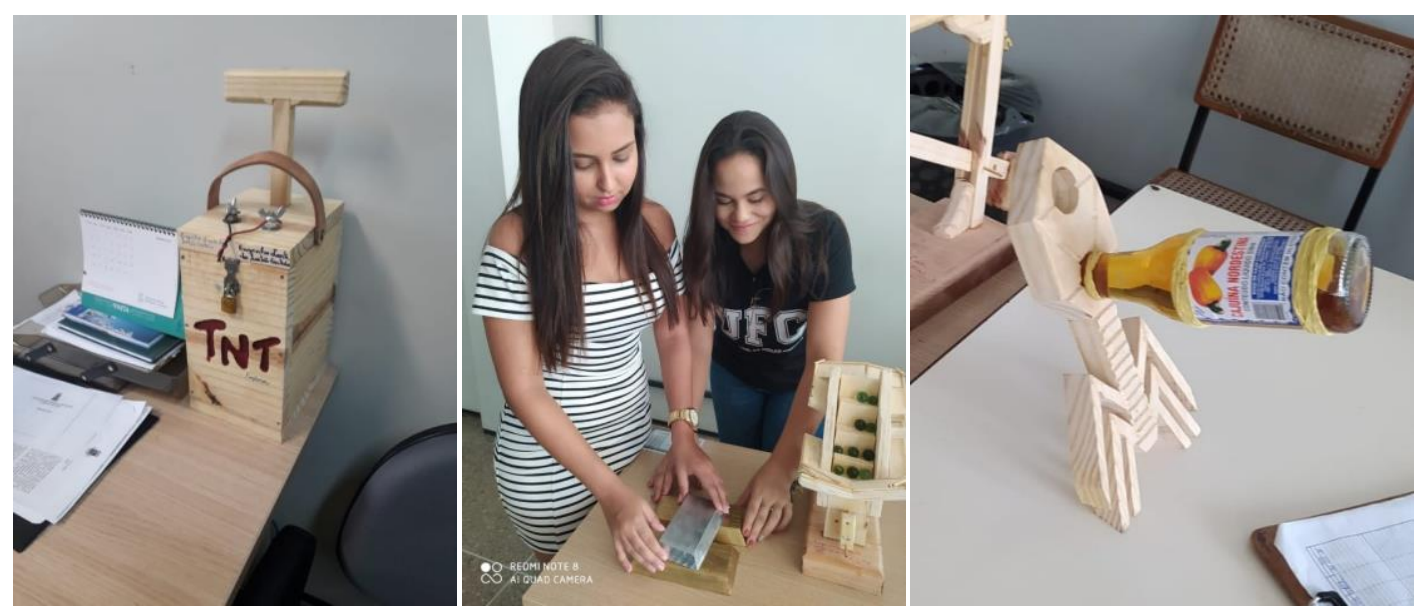

Fonte: Autores

As demais peças foram instaladas no campus Crateús da UFC, como: casa de passarinho, casa de coruja, comedouro de passarinho, casa para morcegos, balançador, sino dos ventos. Outras foram distribuída para a população carente da cidade, como cofrinho de madeira, cacto de corrente de moto, quadros rústico de pedrisco e outro balançador, Figura 9. 
Figura 8 - Outras peças do projeto

\section{Fonte: Autores}
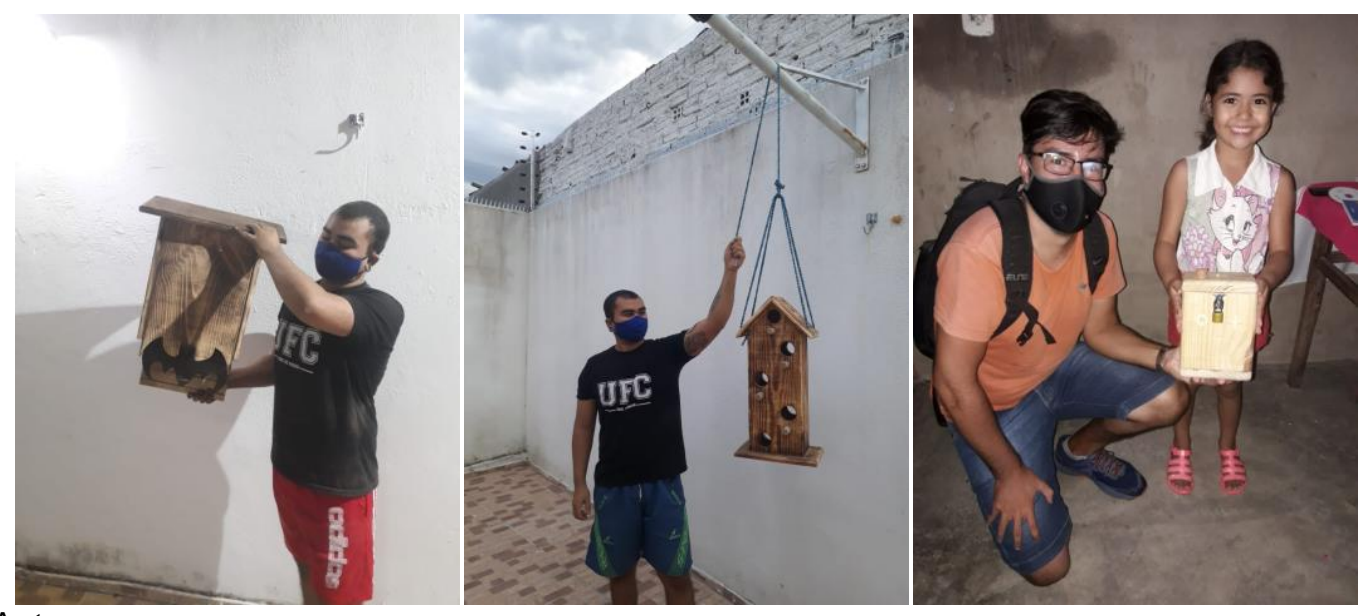

Foram colhidos vários e extensos depoimentos que salientaram aspectos, como: o caráter social do projeto; iniciativa relevante; aproximação entre comunidade e universidade; aprendizagem lúdica; caráter reflexivo; disseminação de conhecimento; criatividade; enriquecimento cultural.

Percebe-se a relevância para a comunidade acadêmica pelo depoimento da estudante:

"O projeto Engenho D'Arte do Sertão de Crateús foi de suma importância para a interação de todos no Campus, além de ver na prática por meio das peças expostas, a engenharia de outro ângulo, visto que era necessário atenção e estratégia para a execução dos jogos. Isso nos mostra que aprender de forma lúdica é imprescindível para o conhecimento, pois facilita o entendimento, além da interação com outros.", (Joice Maria de Paiva, 2020).

Neste depoimento é notório a influência que o projeto teve para melhorar a interação da comunidade acadêmica e contribuir com a significância do conhecimento teórico.

No depoimento de um dos bolsistas do projeto é possível refletir sobre o enriquecimento que trouxe o projeto para os seus participantes:

"O projeto Engenho D'Arte do Sertão de Crateús, me proporcionou uma grande diversidade de conhecimento, tanto com a história da região, que foi ainda mais abordada, como também, com os materiais utilizados no projeto. O projeto além disso, me fez desenvolver e aprimorar novas habilidades que até então, desconhecia. A experiência de fazer parte do Engenho D'Arte do Sertão de Crateús, é muito gratificante e enriquecedor, pois nele, a criatividade e diversas outras habilidades que um Engenheiro deve possuir, é de grande relevância para o mercado de trabalho quanto para a vida toda. O projeto ainda possibilita além da interação dos alunos com os servidores, possibilita também, que a comunidade em si, seja acadêmica ou não acadêmica, desenvolvam habilidades e criem belas artes que enriqueçam a cultura da nossa região e podendo até, ser uma fonte de renda para a população.", (Antônio Ítalo Rodrigues, 2020). 
Neste depoimento observa-se a contribuição diversificada do projeto, desde habilidades técnicas até sociais, contribuindo na construção da formação cidadã no campus.

Como resultado, os alunos participantes desenvolveram maior proatividade, desenvoltura pública e consciência social, além disso, percebe-se maior reflexão social em relação aos assuntos sobre melhoria do bem-estar físico do campus. Isto leva a aquisição de competências humanísticas necessárias a formação cidadã do profissional preocupado com bem-estar do seu entorno e reforça o caráter extensionista da universidade.

\section{CONSIDERAÇÕES FINAIS}

O projeto encontra-se em andamento, mas já é possível perceber a relevância na formação cidadã do discentes do campus Crateús. Esta constatação é possível por se notar nos participantes do projeto uma maior reflexão sobre os aspectos sociais do campus, por terem desenvolvido maior desenvoltura social, cooperação e pelo empenho em construir soluções que melhorem o ambiente comunitário. Reforça essa conclusão o fato de: a comunidade acadêmica ter se envolvido na participação das ações, refletido mais sobre a necessidade de atuarem de forma cidadã na construção do campus e terem se entretido e divertido no ambiente acadêmico, o que demonstra que as ações de cunho cidadã promovidas pelos próprios alunos tiveram impactos sociais significativos na melhoria do ambiente acadêmico. Desta forma, chega-se a conclusão que a própria comunidade acadêmica pode ser motor da melhoria de vários aspectos ligados ao bemestar comunitário, tendo como benefícios acadêmicos: um melhor ambiente físico, reforço do caráter extensionista da universidade e uma formação profissional humanística de todos.

REFERÊNCIAS

BRASIL. Resolução no 2, de 24 de abril de 2019: Institui as Diretrizes Curriculares Nacionais do Curso de Graduação em Engenharia.Diário Oficial da União. Brasília. 26 de Abril de 2019. Edição: 80, Seção: 1, Página: 43.

MACEDO, K. D. S. et al., Metodologias ativas de aprendizagem: caminhos possíveis para inovação no ensino em saúde. Esc. Anna Nery [online]. vol. 22, n. 3, 2018.

SILVA, Mônica Ribeiro da. Educação e a formação do cidadão. Educ. rev. [online]. 1995, n.11 [citado 2020-08-09], pp.129-134. Disponível em: <http://www.scielo.br/scielo.php?script=sci_arttext\&pid=S010440601995000100018\&Ing=pt\&nrm=iso>. ISSN 0104-4060. http://dx.doi.org/10.1590/01044060.152. Acessado em: 01 de Junho 2020.

\section{ENGENHO D'ARTE DO CRATEÚS SERTÃO IN CITIZEN FORMATION}

Abstract: Engenho d'arte do Sertão de Crateús is a multidisciplinary extension project that seeks through the academic community of the campus to generate physical improvements 
that impact the well-being of the academic community itself. Through actions, in the thematic areas of art or culture, actions are carried out on the Crateús campus of the Federal University of Ceará that reach everyone who experiences the campus. In addition, the major role in the design and execution of the project is the students who carry out the activities aided by the project's teachers and servants and expose them to the academic community. This community has been very receptive to this type of action and has evaluated the performance of the project in a positive way. Engenho d'arte has contributed to the construction of a citizen formation through the performance in the academic physical space, with improvements through games, gadgets and art that mix engineering, creativity and humanity.

Key-words: Engenho d'arte do Sertão de Crateús. Citizen Formation. Community wellbeing. 